FOLIA

Amazónico

Revista del Instituto de Investigaciones

de la Amazonía Peruana

\title{
DISTRIBUCIÓN ESPACIAL DE AGUAJALES MEDIANTE CLASIFICACIÓN SUPERVISADA DE IMÁGENES DE SATÉLITE DE LA REGIÓN UCAYALI, PERÚ
}

\author{
Jorge Manuel REVILLA CHÁVEZ ${ }^{1}$, David LLUNCOR MONTALVAN ${ }^{2}$, \\ Diego Gonzalo GARCIA SORIA ${ }^{1}$, Krystel ROJAS MEGO ${ }^{1}$, \\ Carlos ABANTO RODRIGUEZ ${ }^{1}$, Wilson Francisco GUERRA AREVALO ${ }^{1}$, \\ Kember MEJIA CARHUANCA ${ }^{3}$, Dennis DEL CASTILLO TORRES ${ }^{3}$
}

1 Instituto de Investigaciones de la Amazonía Peruana - IIAP, Pucallpa, Perú. Correo electrónico: jrevilla@iiap.gob.pe

2 Gerencia Regional Forestal y de Fauna Silvestre Ucayali, Pucallpa, Perú.

3 Instituto de Investigaciones de la Amazonía Peruana - IIAP, Iquitos, Perú.

\section{RESUMEN}

Los aguajales, son ecosistemas con presencia predominante de aguaje Mauritia flexuosa, aportan importantes beneficios socioeconómicos y ambientales a los pobladores de la Amazonía peruana. Este estudio tiene como objetivo determinar la extensión de aguajales en la región Ucayali, Perú, mediante el método de clasificación supervisada de imágenes de satélite generadas por el satélite de Observación Terrestre LANDSAT 8 a través del sensor OLI-TIRS, correspondiente a la región Ucayali en el año 2017. La extensión de aguajales se ha determinado también mediante la interpretación visual en la combinación de bandas 5 (Infrarrojo Cercano (NIR), con longitud de onda de 0,85 - 0,88 $\mu \mathrm{m}$ ), 6 (Infrarrojo de Onda Corta 1 (SWIR 1), con longitud de onda de 1,57 - 1,65 $\mu \mathrm{m}$ ) y 2 (Azul, con longitud de onda de 0,45 - 0,51 $\mu \mathrm{m}$ ), para la obtención del mapa de aguajales con escala de interpretación de 1:100 000 y con un área mínima de mapeo de 5,00 ha. con lo que determinamos una extensión de 65 120,04 ha de aguajales en la región Ucayali. La identificación de la ubicación y superficie neta de los bosques de aguajales en la región Ucayali permitirá desarrollar estudios futuros sobre sus beneficios potenciales, el manejo y aprovechamiento de los frutos y los servicios ambientales, así como contar con información para una mejor gobernanza en un contexto de cambio climático.

PALABRAS CLAVE: Mauritia flexuosa, Amazonía, análisis de imágenes, procesamiento de imágenes. 


\title{
SPATIAL DISTRIBUTION OF PALM SWAMP THROUGH SUPERVISED CLASSIFICATION OF SATELLITE IMAGES OF UCAYALI REGION, PERU
}

\begin{abstract}
Palm swamps are ecosystems with a predominant presence of the palm Mauritia flexuosa, which provides important socio-economic and environmental benefits to the inhabitants of the Peruvian Amazon. The objective of this study is to determine the extent of palm swamp forest in the Ucayali region, Peru, through the supervised classification method of satellite images generated by the LANDSAT 8 Earth Observation satellite through the OLI-TIRS sensor, corresponding to Ucayali region in 2017. We visually interpreted the combination of bands 5 (Near Infrared (NIR), with wavelengths of $0.85-0.88 \mu \mathrm{m}$ ), 6 (Short Wave Infrared 1 (SWIR 1), with wavelengths of $1.57-1.65 \mu \mathrm{m}$ ) and 2 (Blue, with wavelengths of $0.45-0.51 \mu \mathrm{m}$ ) to obtain the map of palm swamp forest with an interpretation scale of 1:100 000 and a minimum mapping area of 5.00 ha. We determined a coverage of 65120.04 ha of palm swamp forest in the Ucayali region. Identifying the location and net area of palm swamp forests in the Ucayali region will allow further understanding of their potential benefits, management and utilization of fruits, environmental services and also information for better management in the context of climate change.
\end{abstract}

KEYWORDS: Mauritia flexuosa, Amazonia, image analysis, image processing. 


\section{INTRODUCCIÓN}

Los aguajales son bosques con predominancia de la palmera Mauritia flexuosa L.F. (Arecaceae), especie nativa de la Amazonía que se distribuye en regiones bajas y mal drenadas de América del Sur (Muller, 1970; González, 1987). Mauritia flexuosa se conoce comúnmente como carandayguazu e ideuí en Bolivia; buriti, burití-do-brejo, miriti, buritirana en Brasil; canangucha, moriche, aguaje, mirití en Colombia; aguaje en Perú; y moriche en Venezuela. Se distribuye en tierras ácidas y anegadas de Brasil, Colombia, Bolivia, Venezuela, Surinam, Guyana Francesa, Guyana Inglesa y Trinidad (Garzón \& Leyva, 1993; Domínguez, 1993; Henderson, 1995; Cabrera \& Wallace, 2007).

En el Perú, los bosques de palmeras o aguajales tienen una extensión de 5570736 ha y cubren el 4,33\% del total del territorio nacional. La mayor extensión de aguajales se encuentra en la depresión del Abanico del Pastaza y la depresión Ucamara, en el departamento de Loreto, mientras que en la llanura inundable de los ríos Amazonas, Ucayali, Huallaga, Pastaza, Tigre, Napo, Santiago y Putumayo, están presentes en menor proporción (MINAM, 2015).

Los aguajales tienen gran importancia social, económica y ambiental en la Amazonía peruana (Del Castillo et al., 2006). El aguaje es un producto forestal no maderable con múltiples usos para las comunidades indígenas y rurales, principalmente asociadas con alimentos, fibras, forraje animal y construcción (Paniagua et al., 2007; Goodman et al., 2013). Los frutos del aguaje son una fuente importante de vitaminas y proteínas para las comunidades rurales (Pacheco, 2005). Aunque el fruto del aguaje se destaca como la parte más usada de la palmera, otras partes de la planta, como hojas, aceites y otros productos tienen un papel importante económicamente (Virapongse et al., 2017).

En la región Ucayali, el aguaje es el producto forestal no maderable que genera mayores ingresos monetarios mensuales en los mercados de la ciudad de Pucallpa (Baltazar, 2011). Además, los aguajales en zonas bajas inundables son los mayores depósitos de carbono en los bosques de Ucayali, con un total de 304,6 tCha-1 (García et al., 2012), secuestran $\mathrm{CO}_{2}$ atmosférico y regulan el drenaje, del mismo modo tienen buena resiliencia a cambios ambientales naturales (Charman et al., 2008), pero son muy sensibles a la actividad antrópica.

La práctica más común de cosechar el fruto de $M$. flexuosa implica la tala de las plantas que producen frutos (aguajes hembras), lo que provoca una reducción localizada en la población de palmeras adultas (Delgado et al., 2007; Manzi \& Coomes, 2009; Falen \& Honorio, 2018; Horn et al., 2018). En las últimas décadas, la creciente demanda local y regional de frutos de M. flexuosa ha tenido como resultado una mayor presión sobre los aguajales (Endress et al., 2013). La eliminación selectiva de aguajes hembras reduce la fuente de semillas, dificultando la regeneración natural y el reclutamiento de nuevas palmeras de M. flexuosa (Horn et al., 2012), alterando la estructura y composición de los bosques de $M$. flexuosa, disminuyendo severamente la ecología, integridad y pérdida de servicios ecosistémicos derivados de estos bosques. La degradación de los bosques de $M$. flexuosa podría potencialmente desestabilizar los depósitos de turba y reducir su capacidad para secuestrar y almacenar carbono (Bhomia et al., 2018), factores importantes para regular el clima y controlar las concentraciones de $\mathrm{CO}_{2}$ atmosférico.

Es por ello que la gestión se vuelve de vital importancia para la sostenibilidad de los aguajales, 
más aún teniendo en cuenta la extensión que ocupan en la Amazonía. El uso de técnicas de sensores remotos, es una herramienta de utilidad para la realización de estudios relacionados con suelos, vegetación, litología, geomorfología y otros similares. Mediante esta herramienta se extrae información de las imágenes satelitales a través del análisis digital, que puede mejorarse al incluirse medidas de espectro-radiometría y/o comprobación de campo (Carpintero et al., 2007). El presente estudio integra técnicas de sensoramiento remoto e interpretación visual de imágenes satelitales para la determinación de los aguajales en la región de Ucayali.

\section{MATERIAL Y MÉTODOS}

\section{ÁREA DE ESTUDIO}

El estudio comprende la región Ucayali, en la parte centro-oriental del territorio peruano y la llanura inundable del río Ucayali, al este de la Cordillera de los Andes. Es la quinta región en extensión a nivel nacional, con una superficie de 102 410,55 $\mathrm{km}^{2}$, equivalente al 7,9\% del territorio nacional y al 13,2 \% de territorio amazónico, siendo la segunda región amazónica más extensa del Perú, después de Loreto (Figura 1).

Geográficamente presenta los siguientes límites: al norte la región Loreto, al sur las regiones de Junín, Cuzco y Madre de Dios, al oeste las regiones de Huánuco, Pasco, y al este con la República del Brasil. Así mismo, la región Ucayali está conformada por cuatro provincias: Atalaya, Coronel Portillo, Padre Abad y Purús.

\section{METODOLOGÍA}

Para la determinación de los aguajales se utilizaron nueve bandas de las imágenes de satélite de observación LandSat 8 de la región Ucayali, de sensor satelital OLI-TIRS (Figura 2: a), descargados del repositorio de imágenes digital del portal GLOVIS (https://glovis.usgs.gov/), cuyas características se muestran en la Tabla 1 y 2.

Figura 1: Ubicación de la región Ucayali, Perú.

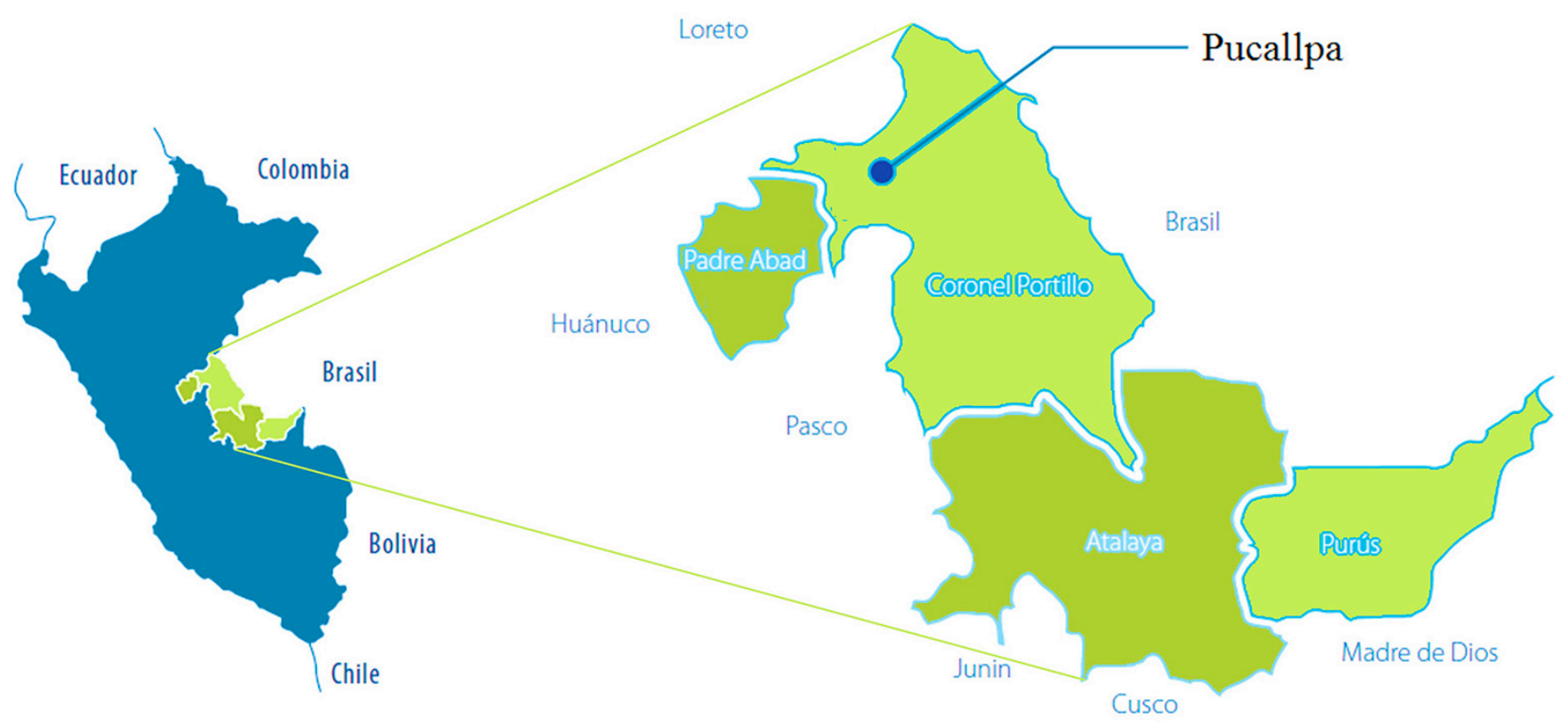




\section{RECURSOS INFORMÁTICOS Y DIGITALES}

Se realizó el procesamiento de nueve imágenes satelitales de nivel de procesamiento $1 \mathrm{~T}$ (no requieren corrección atmosférica) de los meses de julio, agosto y septiembre del año 2017, cubriendo la extensión de la región Ucayali. Teniendo como criterio de selección las escenas que presentaron un máximo de $10 \%$ de nubosidad, las seleccionadas se listan en la Tabla 1. El procesamiento se realizó con software licenciado ArcGis 10.4.

Tabla 1: Imágenes satelitales LANSAT 8 sensor OLI (30 m resolución espacial).

\begin{tabular}{cccccc}
\hline No & Imagen & $\begin{array}{c}\text { Datum } \\
\text { Horizontal }\end{array}$ & Esferoide & Proyección & Zona \\
\hline 1 & LC08_L1TP_004067_20170724_20170809_01_T1 & WGS84 & WGS84 & UTM & 18 Sur \\
2 & LC08_L1TP_004068_20170724_20170809_01_T1 & WGS84 & WGS84 & UTM & 18 Sur \\
3 & LC08_L1TP_005066_20170715_20170727_01_T1 & WGS84 & WGS84 & UTM & 18 Sur \\
4 & LC08_L1TP_005067_20170715_20170727_01_T1 & WGS84 & WGS84 & UTM & 18 Sur \\
5 & LC08_L1TP_005068_20170816_20170825_01_T1 & WGS84 & WGS84 & UTM & 18 Sur \\
6 & LC08_L1TP_006065_20170722_20170728_01_T1 & WGS84 & WGS84 & UTM & 18 Sur \\
7 & LC08_L1TP_006066_20170722_20170728_01_T1 & WGS84 & WGS84 & UTM & 18 Sur \\
8 & LC08_L1TP_006067_20170722_20170728_01_T1 & WGS84 & WGS84 & UTM & 18 Sur \\
9 & LC08_L1TP_007066_20170830_20170915_01_T1 & WGS84 & WGS84 & UTM & 18 Sur \\
\hline
\end{tabular}

Figura 2: Fases de clasificación supervisada; a. Selección de imágenes Landsat 8 con 10 \% de cobertura de nubes o menos (meses de junio, julio, agosto 2017); b. Ubicación de las coordenadas de los aguajales ubicados en campo combinación de bandas y composición a falso color de las imágenes a procesar;

c. Selección del mejor algoritmo de clasificación (Maximun Likelihood); d. Determinación de los parámetros necesarios para ejecutar la clasificación supervisada (áreas de entrenamiento, firmas espectrales, etc.);

e. Aplicación del algoritmo; f. Evaluación visual del resultado de la clasificación; g. Delimitación de áreas identificadas y verificación con imágenes de alta resolución (Google Earth); h. Depuración de áreas identificadas; i. Mapa temático de aguajales de la región Ucayali, Perú.

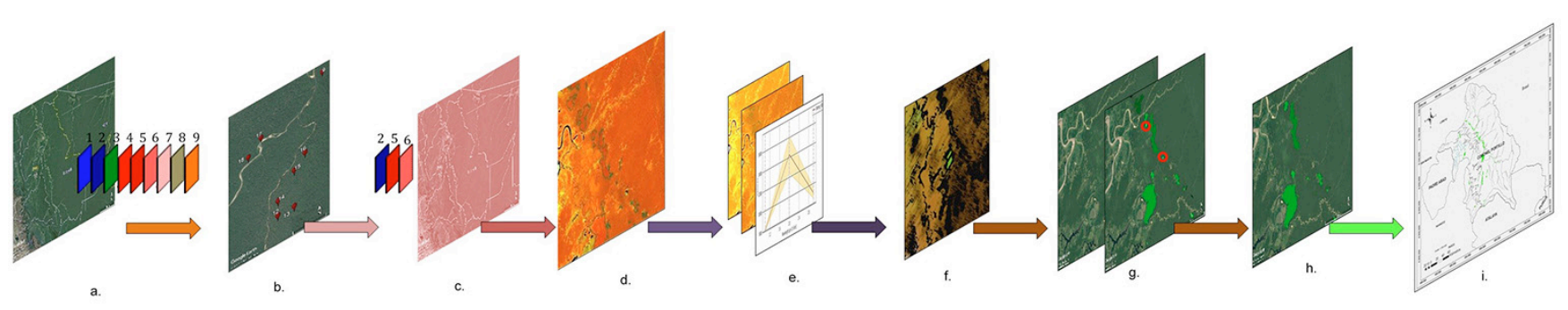


Tabla 2: Características de imágenes satelitales LANSAT 8 sensor OLI.

\begin{tabular}{clcc}
\hline Banda & Nombre de Banda & Rango Espectral $(\mu \mathrm{m})$ & Resolución \\
\hline 1 & Azul Profundo & $433-453$ & $30 \mathrm{~m}$ \\
2 & Azul & $450-515$ & \\
3 & Verde & $525-600$ & \\
4 & Rojo & $630-680$ & $30 \mathrm{~m}$ (Bandas \\
5 & Infrarrojo Cercano & $845-885$ & Heredadas del Sensor \\
6 & Infrarrojo de onda corta 2 & $1560-1650$ & \\
7 & Infrarrojo de onda corta 3 & $2100-2300$ & \\
8 & Pancromático & $500-680$ & \\
9 & Infrarrojo de onda corta & $1360-1390$ & \\
\hline
\end{tabular}

Tabla 3: Puntos de verificación de campo para obtención de firma espectral en áreas de aguajales en la región Ucayali, Perú.

\begin{tabular}{|c|c|c|c|c|c|c|}
\hline \multirow{2}{*}{$N^{\circ}$} & \multicolumn{2}{|c|}{ Coordenadas } & \multirow{2}{*}{ Localidad } & \multirow{2}{*}{ Distrito } & \multirow{2}{*}{ Provincia } & \multirow{2}{*}{ Departamentc } \\
\hline & E & $\mathrm{N}$ & & & & \\
\hline 1 & 595890 & 9062120 & Abujao & Masisea & Coronel Portillo & Ucayali \\
\hline 2 & 596338 & 9062143 & Abujao & Masisea & Coronel Portillo & Ucayali \\
\hline 3 & 590582 & 9065809 & Abujao & Masisea & Coronel Portillo & Ucayali \\
\hline 4 & 596290 & 9062234 & Abujao & Masisea & Coronel Portillo & Ucayali \\
\hline 5 & 542330 & 9058460 & Tupac Amaru & Manantay & Coronel Portillo & Ucayali \\
\hline 6 & 542306 & 9057401 & Tupac Amaru & Manantay & Coronel Portillo & Ucayali \\
\hline 7 & 542389 & 9057985 & Tupac Amaru & Manantay & Coronel Portillo & Ucayali \\
\hline 8 & 542561 & 9059192 & Tupac Amaru & Manantay & Coronel Portillo & Ucayali \\
\hline 9 & 436479 & 9020464 & Mariscal Cáceres & Padre Abad & Coronel Portillo & Ucayali \\
\hline 10 & 440681 & 9023343 & Mariscal Cáceres & Padre Abad & Coronel Portillo & Ucayali \\
\hline 11 & 441000 & 9022953 & Mariscal Cáceres & Padre Abad & Coronel Portillo & Ucayali \\
\hline 12 & 435071 & 9016166 & Mariscal Cáceres & Padre Abad & Coronel Portillo & Ucayali \\
\hline 13 & 435577 & 9016167 & Mariscal Cáceres & Padre Abad & Coronel Portillo & Ucayali \\
\hline 14 & 435067 & 9016641 & Mariscal Cáceres & Padre Abad & Coronel Portillo & Ucayali \\
\hline 15 & 435558 & 9017371 & Mariscal Cáceres & Padre Abad & Coronel Portillo & Ucayali \\
\hline 16 & 435901 & 9017775 & Mariscal Cáceres & Padre Abad & Coronel Portillo & Ucayali \\
\hline 17 & 434428 & 9019231 & Mariscal Cáceres & Padre Abad & Coronel Portillo & Ucayali \\
\hline 18 & 434032 & 9018760 & Mariscal Cáceres & Padre Abad & Coronel Portillo & Ucayali \\
\hline
\end{tabular}




\section{PROCESAMIENTO DE IMÁGENES}

El procesamiento se inició con la superposición de 18 puntos de aguajales verificados en campo en coordenadas UTM con un GARMIN GPSMAP 78S (Figura 3: b; Tabla 3) sobre las imágenes disponibles, se prosiguió con la combinación de bandas para resaltar las áreas de aguajales, siendo la de mejor realce la combinación de bandas 5, 6 y 2 para una composición en falso color (Figura 2: c). Luego se asignó valores numéricos a los pixeles de las celdas coincidentes con los puntos de verificación de campo, haciendo uso del software Maximum Likelihood Classification, se ensayó el mejor algoritmo de los puntos verificados en campo, los criterios se capturaron para su utilización en la clasificación supervisada (Figura 2: d, e). En base a parámetros visuales y a la información del algoritmo, se generó una nube de pixeles, marcando texturas digitales identificadas como aguajales potenciales (Figura 2: d, f).

Se realizó el análisis visual, posterior delimitación y vectorización manual delas áreas de mayor concentración de pixeles resultantes de la clasificación, con descarte deáreas sin condiciones fisiográficas para aguajales (Figura 2: g, h), dando énfasis en zonas de mayor concentración de pixeles coincidentes a la clasificación. Para la verificación visual de la cobertura determinada se usaron las imágenes de los mapas temáticos de la ZEE de la región Ucayali (2017), el Mapa Nacional de Cobertura Vegetal (MINAM, 2015) e imágenes de alta resolución de Google Earth, con lo que se procedió a la depuración de resultados no coincidentes de coberturas en campo.

La aplicación del proceso resultó en la delimitación de capa de cobertura de aguajales para la región Ucayali (Figura 2: i), en la escala de interpretación de 1:100 000 con área mínima cartografiable de 5,00 ha, tomando en cuenta que el área mínima cartografiable aceptable para imágenes Landsat es de 30 m de resolución, con
Tabla 4: Área (ha) de aguajales de la región Ucayali y provincias del año 2017.

\begin{tabular}{ccr}
\hline$N^{\circ}$ & Provincias & Extensión (ha) \\
\hline 1 & Padre Abad & 409,01 \\
2 & Coronel Portillo & 59272,00 \\
3 & Atalaya & 4380,02 \\
4 & Purús & 1059,01 \\
Total & & 65120,04 \\
\hline
\end{tabular}

una precisión planimétrica de 50 m (Lencinas \& Siebert 2009).

\section{RESULTADOS}

Basados en la interpretación visual a partir de los resultados de la clasificación supervisada del raster generado por la combinación de bandas del estudio, se encontró que el área de aguajales en la región Ucayali es de 65 120,04 ha (Figura 4).

Del mismo modo, se determinó que la mayor concentración de aguajales se encuentra en la provincia de Coronel Portillo (Tabla 4 y Figura 4).

\section{DISCUSIÓN}

El estudio de Zonificación Ecológica y Económica (ZEE) de la región Ucayali (GOREU, 2017) es el documento técnico de gestión del territorio vigente, en torno al cual se compararon los distintos resultados generados principalmente por la Oficina Nacional de Evaluación de Recursos Naturales (ONERN) y el Organismo de Supervisión de los Recursos Forestales y de Fauna Silvestre (OSINFOR). El GOREU (2017), utilizando la metodología Corine Land Cover, estimó que las poblaciones naturales de aguaje de la región Ucayali alcanzan una extensión de 25 533,12 ha (OR. N017-2017), sin embargo, el mismo GOREU (2008), reportó una extensión de 55 781,21 ha. 
Figura 3: a. Puntos de validación de campo de aguajales en la región Ucayali, Perú; b. Distrito de Manantay; c. Distrito de Padre Abad; d. Distrito de Masisea.
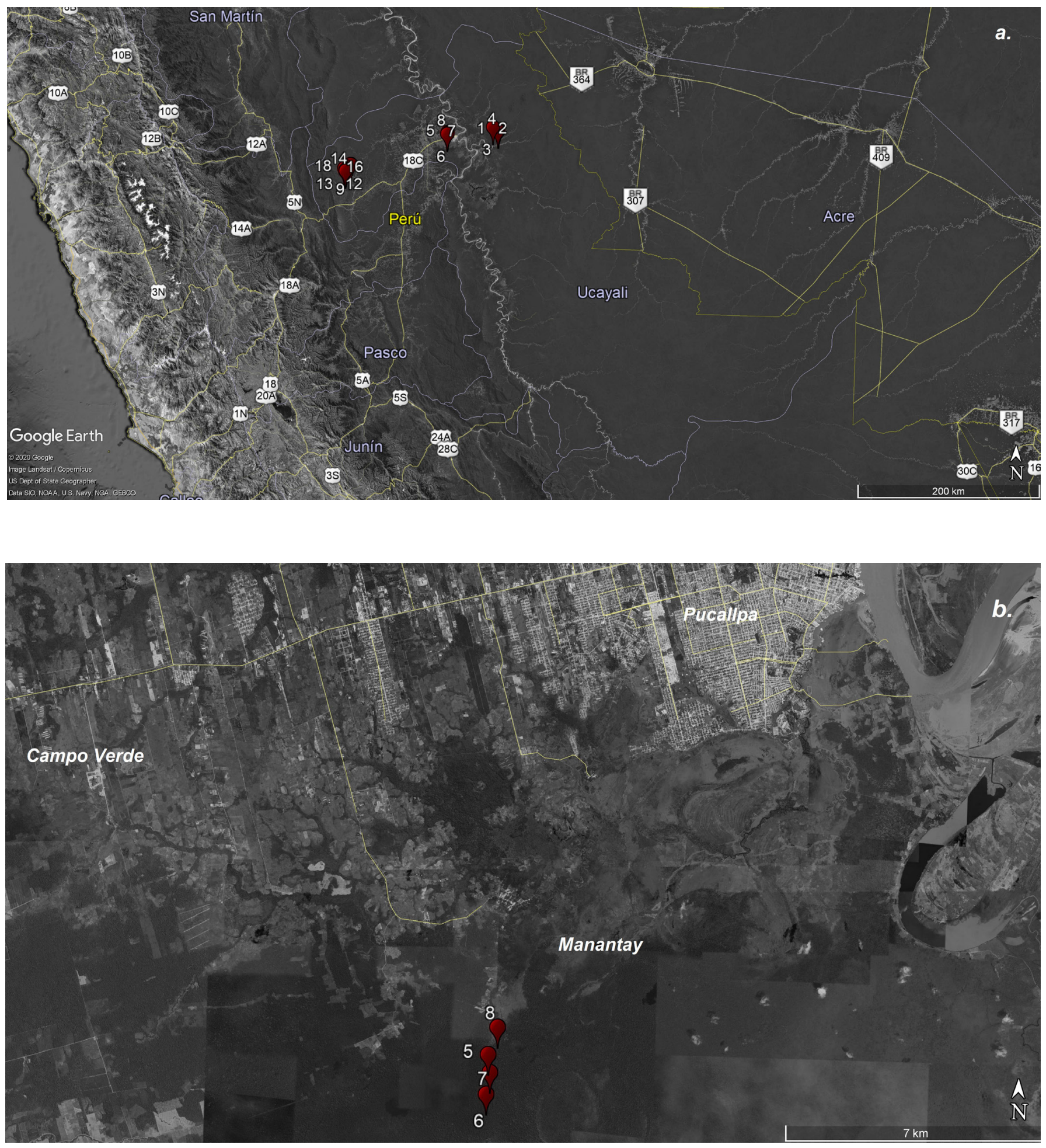

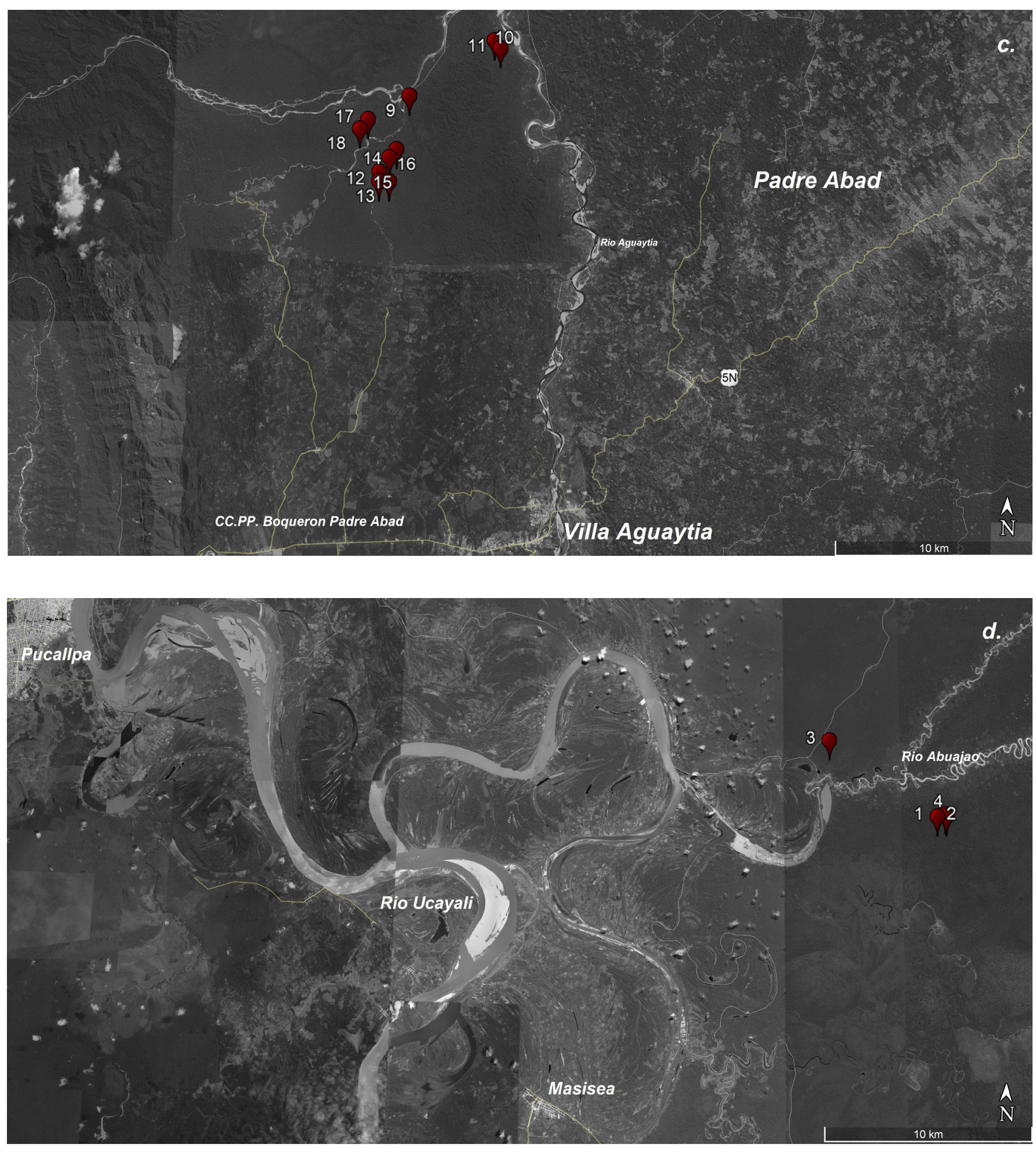
Figura 4: a. Aguajales de la región Ucayali, Perú; b. Provincia de Coronel Portillo; c. Provincia de Padre Abad; d. Provincia de Atalaya; e. Provincia de Purús.
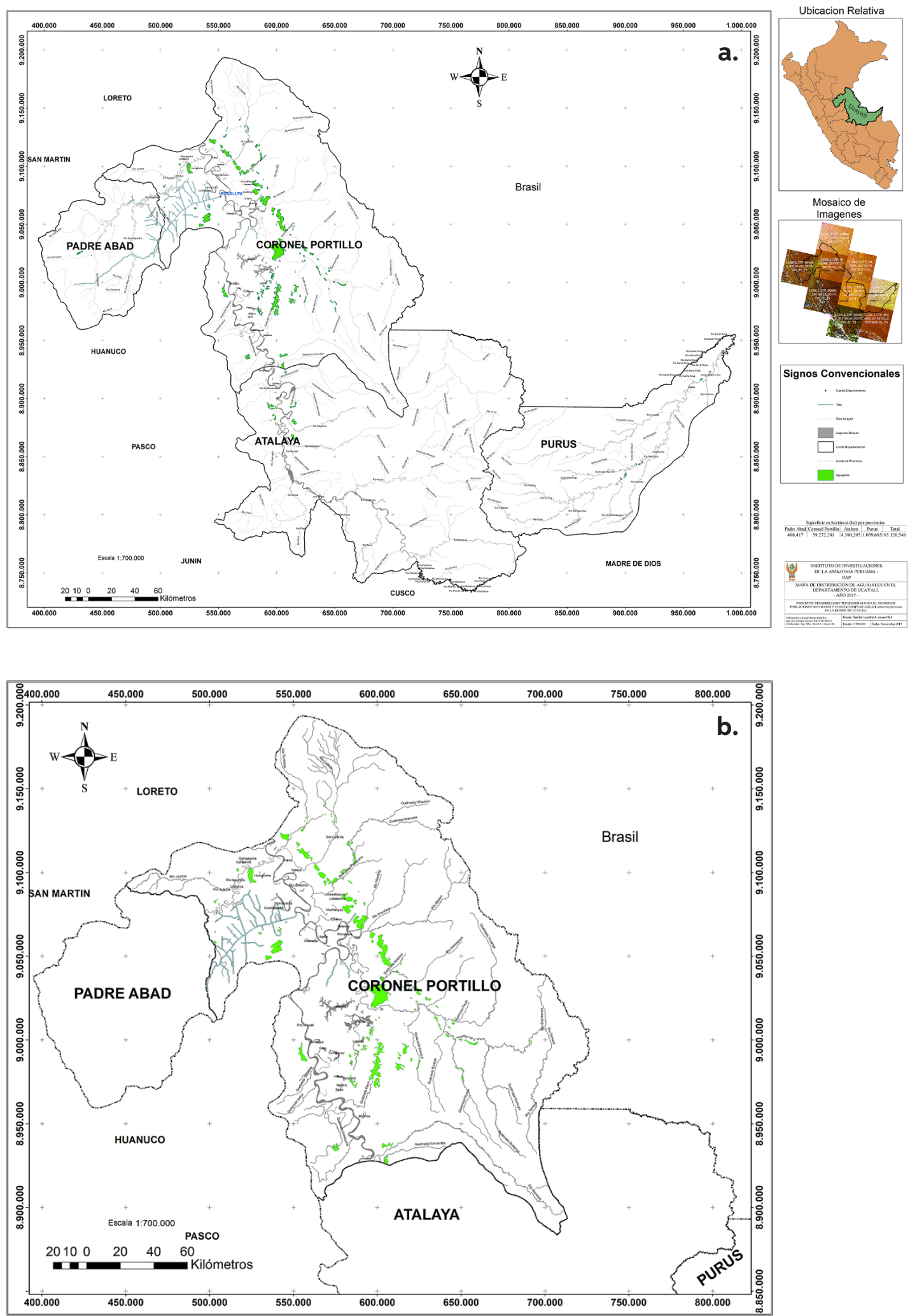

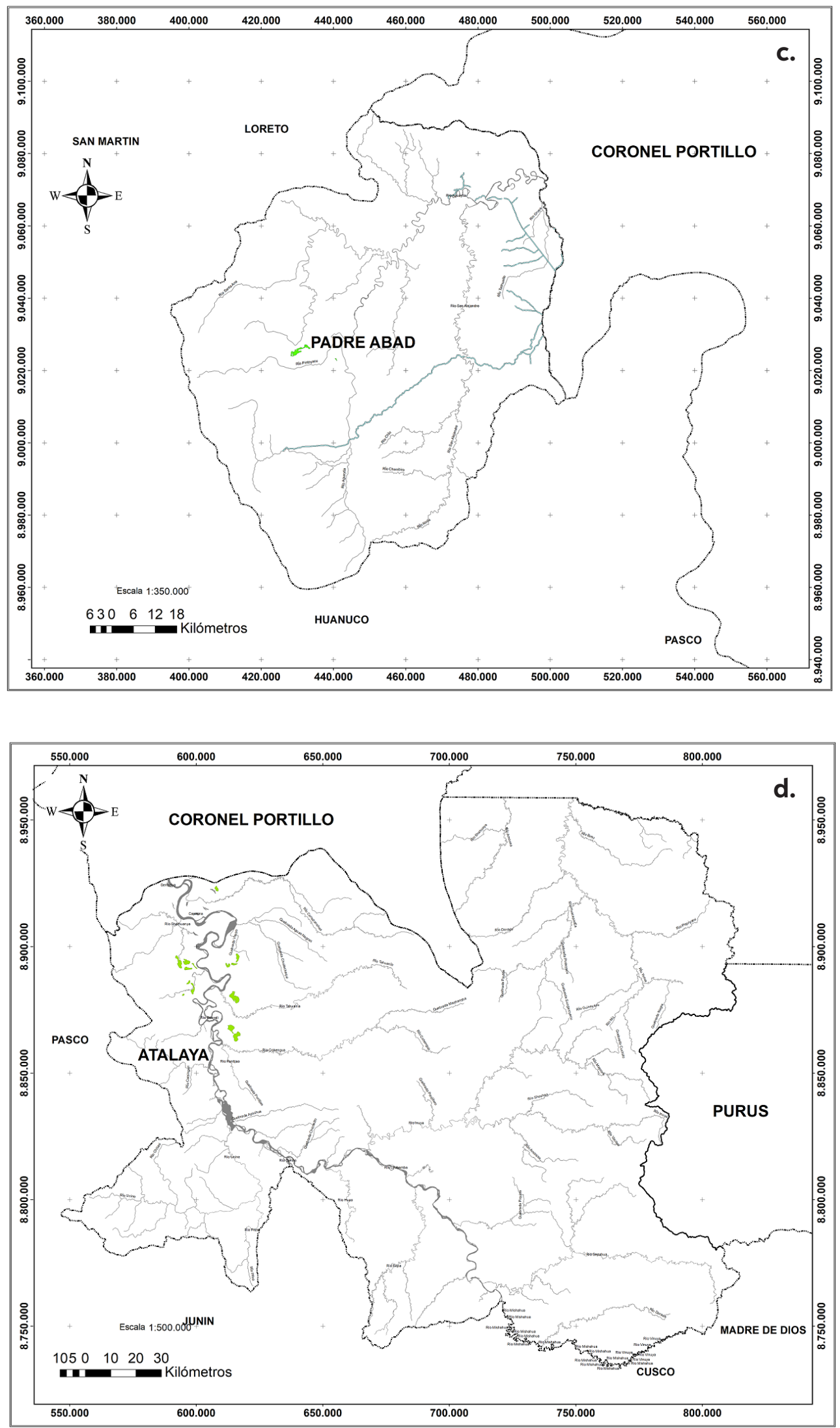


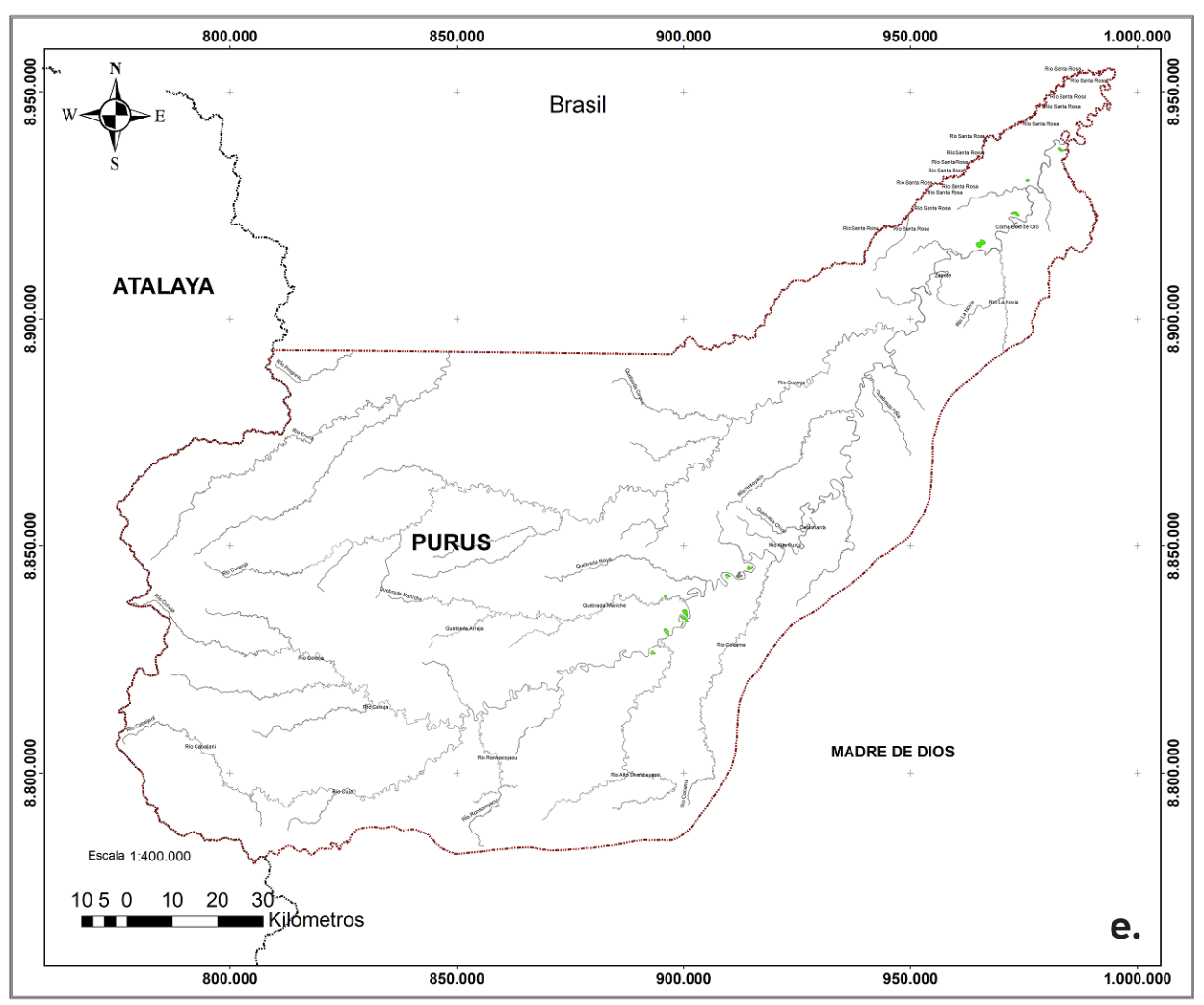

Blanco (1986) reportó 61000 ha de aguajales propiamente dichos. Del mismo modo la ONERN (1978), reportó 59500 ha entre zonas de aguajal y bajial en una extensión de 900000 ha en el distrito de Calleria, basándose en fotografías aéreas, mosaicos cartográficos y mosaicos de imágenes de radar de vista lateral (SLAR), de los cuales 39500 ha son aguajales y 20000 ha son bajiales. También la ONERN (1995) determinó 55 667,00 ha de aguajales, en base a imágenes LANDSATMSS en las bandas 4, 5 y 7 a escala $1 / 1$ 000000 del año 1988 e imágenes LANDSAT-TM en las bandas 3, 4 y 5, a escala 1/250 000 de los años 1984-1991. Mientras que OSINFOR (2013) usando nueve imágenes de satélite Landsat TM 5 con resolución de 30 metros del año 2011 (cobertura total) y ocho imágenes de satélite ALOS AVNIR con resolución de 10 metros año 2009-2010 (cobertura parcial) reportó que la extensión de aguajales y/o humedales en Ucayali es de 84732 ha. Estas diferencias se deben a los distintos sistemas de clasificación de bosques utilizados por los autores y la tecnología variable usada en distintos momentos.

En este contexto, el resultado obtenido en el presente estudio es similar a lo reportado por Blanco (1986), quien utiliza un sistema de clasificación de aguajales propiamente dichos. Mientras que la ONERN (1978), utiliza la clasificación de zonas de aguajal y bajial para sus resultados y OSINFOR (2013) obtiene sus resultados basados en la clasificación de aguajales y humedales. Estos resultados se acercan a los obtenidos en el presente estudio a diferencia de los obtenidos por GOREU (2017), lo que refuerza la disparidad de los resultados basados en los distintos tipos de clasificación de bosques utilizados.

El factor tecnológico en estudios de sensoramiento remoto genera diferencias en los 
resultados, debido a que las imágenes de satélite en la última década han mejorado significativamente su resolución espacial y temporal, permitiendo observar una mayor gama de variables y transiciones que los observados en los estudios desarrollados por la ONERN, que utilizaron imágenes de radar para expresar una mayor diversidad de tipos de cobertura en un área de escala nacional; por lo que la combinación preliminar de bandas permitió resaltar la textura y atributos visuales de aguajales en la región Ucayali. Del mismo modo, el uso de diferentes softwares ha permitido el análisis dinámico de la combinación de bandas, resaltando las respuestas radiométricas de una mayor amplitud de longitudes de ondas para identificar coberturas con similitud a las firmas espectrales utilizadas. Prueba de ello es que Salitchev (1979), establece que el área mínima cartografiable para imágenes Lansat, a una escala de 1/100 000, es de 16 ha, mientras que Lencina \& Siebert (2009) establecen que el área mínima cartografiable para imágenes Landsat 8, para una resolución de 30 m, a una escala de 1/ 100000 , es de 5,00 ha para una precisión planimétrica de 50 m, esta área es cercana a la definida por Marquina \& Mogollón (2018), para imágenes Landsat 8 de $30 \mathrm{~m}$ de resolución, para una precisión planimétrica de 25 m, cuya área mínima cartografiable es de 6,25 ha.

\section{REFERENCIAS BIBLIOGRÁFICAS}

Baltazar, 0. 2011. Estudio etnobotánico y de mercado de productos forestales no maderables extraídos del bosque y áreas afines en la ciudad de Pucallpa -Perú. Tesis de Pregrado, Universidad Nacional de Ucayali, Pucallpa, 238pp.

Bhomia, R.; Lent, J.; Rios, J; Hergoualc'h, K.; Honorio, E.; Murdiyarso, D. 2018. Impacts of Mauritia flexuosa degradation on the carbon stocks of freshwater peatlands in the Pastaza-
Marañón river basin of the peruvian Amazon. Mitigation and Adaptation Strategies for Global Change, 24. DOI: https://doi.org/10.1007/ s11027-018-9809-9

Blanco, J. 1986. Diagnóstico de la actividad forestal del Departamento de Ucayali. Ministerio de Agricultura, Lima. 273pp.

Cabrera, H.; Wallace, R. 2007. Patrones fenológicos de ocho especies de palmeras en el bosque amazónico de Bolivia. Revista Boliviana de Ecología y Conservación Ambiental, 21: 1-18.

Carpintero, S.; Chica, M.; Rigol, J.P.; Iguzquiza, E.; Galiano, V. 2007. Aplicación de imágenes ASTER y ETM+ para el estudio de la susceptibilidad a la erosión en una zona semiárida (SE España). Revista de Teledetección, 28: 13-23.

Charman, D.J.; Booth, R.K.; Mäkilä, M.; Sirin, A. 2008. Peatlands and past climate change. In: Parish, F.; Sirin, A.; Charman, D.J.; Joosten, H.; Minayeva, T.; Silvius, M.; Stringer, L. (Eds.): Assessment on peatlands, biodiversity and climate change: Main Report. p.39-59.

Del Castillo, D.; Otárola, E.; L. Freitas. 2006. Aguaje: La maravillosa palmera de la Amazonía peruana. Instituto de Investigaciones de Investigaciones de la Amazonía Peruana, Iquitos. 51pp.

Delgado C.; Couturier G.; Mejia, K. 2007. Maurita flexuosa Arecaceae: Calamoideae, an Amazonian palm with cultivation purposes in Peru. Fruits 62: 157-169. DOI: https://doi. org/10.1051/fruits:2007011

Domínguez, A. 1993. Ensayos de procesamiento de "Pijuayo" (Guilielma Gasipaes B.K. - L.H. Bailei) y "Aguaje" (Mauritia flexuosa). Instituto de Investigaciones de la Amazonía Peruana, Iquitos. $\mathrm{s} / \mathrm{p}$

Endress B.A.; Horn C.M.; Gilmore M.P. 2013. Mauritia flexuosa palm swamps: Composition, structure and implications for conservation and management. Forest Ecology and Management. 302: 346-353. DOI: https://doi.org/10.1016/j. foreco.2013.03.051 
Falen L.; Honorio E. 2018. Evaluación de las técnicas de aprovechamiento de frutos de aguaje (Mauritia flexuosa L.f.) en el Distrito de Jenaro Herrera, Loreto, Perú, Folia Amazónica, 27(2): 131-150, DOI: https://doi. org/10.24841/fa.v27i2.443

García, D.; Honorio, E.; Del Castillo, D. 2012. Determinación del stock de carbono en aguajales de la cuenca del río Aguaytía, Ucayali - Perú. Folia Amazónica, 21(1-2): 153-160. DOI: https://doi.org/10.24841/fa.v21i1-2.43

Garzón, C.; Leyva, P. 1993. Perfiles sintéticos sobre especies amazónicas con potencial económico. Perfil N.- 28: Mauritia flexuosa Linn. F. Universidad Nacional de Colombia - Instituto de Ciencias Naturales, Programa de Botánica Económica - Corporación Aracuara - Proyecto Tropenbos, Bogotá. 13pp.

González, B. 1987. Los morichales de los llanos orientales: un enfoque ecológico. CORPOVEN, Caracas. 56pp.

Goodman, R.; Phillips, O.L.; Del Castillo, D.; Freitas, L.; Cortese, S.T.; Monteagudo, A.; Baker, T. 2013. Amazon palm biomass and allometry, Forest Ecology and Management, 310(12): 994-1004. DOI: https://doi.org/10.1016/j. foreco.2013.09.045

GOREU. 2008. Plan vial departamental participativo de Ucayali 2009 - 2018, Ministerio de Transportes y Telecomunicaciones. Pucallpa, 137pp.

GOREU. 2017. Zonificación ecológica económica base para el ordenamiento territorial de la región Ucayali. GOREU, Pucallpa, 223pp.

Henderson, A. 1995. The palms of the Amazon. OUP, New York, 351pp.

Horn, C.M.; Vargas, V.; Gilmore, M.P.; Endress, B. 2018. Spatio-temporal patterns of Mauritia flexuosa fruit extraction in the Peruvian Amazon: Implications for conservation and sustainability. Applied Geography, 97(8):
98-108. DOI: https://doi.org/10.1016/j. apgeog.2018.05.004

Horn, C.M.; Gilmore, M.P.; Endress, B.A. 2012. Ecological and socio-economic factors influencing aguaje (Mauritia flexuosa) resource management in two indigenous communities in the Peruvian Amazon. Forest Ecology and Management. 267(3): 93-103, DOI: https:// doi.org/10.1016/j.foreco.2011.11.040

Lencinas, J. D.; A. Siebert. 2009. Relevamiento de bosques con información satelital: resolución espacial y escala. Quebracho Revista de Ciencias Forestales, 17(1-2): 101-105.

Manzi, M.; Coomes, 0. 2009. Managing amazonian palms for community use: A case of aguaje palm Maurita flexuosa in Peru. Forest Ecology and Management, 257(1): 510-517. DOI: https:// doi.org/10.1016/j.foreco.2008.09.038

Marquina J.; Mogollón A. 2018. Niveles y escalas de levantamiento de información geográfica en sensores remotos. Revista Geográfica Venezolana, 59(1): 42-52.

Ministerio del Ambiente. 2015. Mapa nacional de cobertura vegetal: Memoria descriptiva. Ministerio del Ambiente, Lima. 100pp.

Muller J. 1970. Palynological evidence on early differentiation of Angiosperms. Biological Reviews, 45(3), 417-450. DOI: https://doi. org/10.1111/j.1469-185X.1970.tb01649.x

ONERN. 1978. Evaluación e integración de los recursos naturales de la zona Pucallpa-Abujao. Oficina Nacional de Evaluación de Recursos Naturales - ONERN, Lima. 262pp.

ONERN. 1995. Guía explicativa del mapa forestal INR-49-DGF. Oficina Nacional de Evaluación de Recursos Naturales - ONERN, Lima. 122pp.

OSINFOR. 2013. Evaluación de áreas deforestadas $y$ aguajales en el departamento de Loreto al año 2011. Organismo de Supervisión de los Recursos Forestales y de Fauna Silvestre OSINFOR, Lima. 74pp. 
Pacheco Santos, L. 2005. Nutritional and ecological aspects of buriti or aguaje (Mauritia flexuosa Linnaeus filius): A carotene-rich palm fruit from Latin America. Ecology of Food and Nutrition, 44(5): 345-358. DOI: http://dx.doi. org/10.1080/03670240500253369

Paniagua, N.; Byg, A.; Svenning, J.C.; Moraes, M.; Grandez C.; Balslev, H. 2007. Diversity of palm uses in the western Amazon. Biodiversity and
Conservation, 16(7): 2771-2787. https://doi. org/10.1007/s10531-007-9218-y

Salitchev, K.A. 1979. Cartografía. Pueblo y Educación, La Habana. 182pp.

Virapongse, A.; Endress, B. A.; Gilmore, M. P.; Horn, C.; Romulo, C. 2017. Ecology, livelihoods, and management of the Mauritia flexuosa palm in South America. Global Ecology and Conservation, 10(4): 70-92. DOI: https://doi. org/10.1016/j.gecco.2016.12.005

Recibido: 16 de febrero de 2020 Aceptado para publicación: 27 de junio de 2020 